\title{
Caracterizando os itens de química do novo ENEM na perspectiva da alfabetização científica
}

\author{
Featuring the new ENEM's issues of chemistry \\ in the perspective of the scientific literacy
}

Rafaela Erasmi de Souza Pereira ${ }^{1}$. Leonardo Maciel Moreira ${ }^{1}$

\begin{abstract}
Resumo: O objetivo desta pesquisa é analisar em que medida os itens de química do Exame Nacional do Ensino Médio (ENEM) no período 2009-2015 avaliam a alfabetização científica (AC). Ela dialoga com pesquisas anteriores por discutir a coerência interna do exame e avança por elencar um novo aspecto, a AC. O método utilizado é qualitativo. A matriz de referência e os itens de química foram tratados por análise de conteúdo, com a atribuição em categorias teóricas. Os dados revelaram divergências entre as habilidades e competências pertinentes a AC presentes na matriz de referência e nos itens de química, respectivamente, $17,4 \%$ e $86,6 \%$ (categoria Termos, conhecimentos e conceitos científicos fundamentais), 65,2\% e 13,4\% (categoria Ciência, tecnologia, sociedade e meio ambiente) e 17,4\% e $0 \%$ (categoria natureza da ciência e dos fatores éticos e políticos). Ao final, recomenda-se que o exame avalie, de forma significativa, todas as proposições da AC presentes na matriz de referência.
\end{abstract}

Palavras-chave: Alfabetização científica. Exame de química. Ensino médio. Exame Nacional do Ensino Médio.

\begin{abstract}
The objective of this research is to analyse to what extent the chemistry issues of National High School Examination (ENEM) during 2009-2015 evaluate the scientific literacy (SL). It dialogues with previous research to discuss the internal consistency of the exam and moves forward by listing a new aspect, SL. The method used is qualitative. A reference matrix and chemistry issues were treated by content analysis, with an assignment in theoretical categories. The results showed a divergence between the relevant skills and competences referring to SL and presents in a reference matrix the chemistry issues, respectively, $17.4 \%$ and $86.6 \%$ (category Terms, knowledge and fundamental scientific concepts), $65.2 \%$ and $13.4 \%$ (category Science, technology, society and environment) and $17.4 \%$ and $0 \%$ (category nature of science and ethical and political factors). In the end, it is recommended that the exam evaluate, significantly, all the SL's proposals presented in reference matrix.
\end{abstract}

Keywords: Scientific literacy. Chemistry examination. High School. National High School Examination.

\footnotetext{
${ }^{1}$ Universidade Federal do Rio de Janeiro (UFRJ), Macaé, RJ. Brasil. E-mail: <rafaelaerasmi@macae.ufrj.br>.
} 


\section{Alfabetização Científica}

A alfabetização Científica (AC) foi citada pela primeira vez na literatura ao final da década de 1950 (LAUGKSCH, 2000), sendo considerada sinônimo de entendimento público da ciência. Devido a esta grande abrangência de conceito, a AC assume diversos significados. Dentre as confluências dos diversos autores (CHASSOT, 2003; LEAL; SOUZA, 2002; LORENZETTI; DELIZOICOV, 2001; MILARÉ; RICHETTI, 2008; NIEZER; SILVEIRA; SAUER, 2012; ROSA; TERRAZZAN, 2001), destacam-se o entendimento das relações existentes entre ciência, tecnologia, sociedade e meio-ambiente e a compreensão da natureza da ciência e de conceitos científicos fundamentais. Dessa forma, a AC deve desenvolver, em qualquer pessoa, a capacidade de organizar o pensamento de maneira lógica e auxiliar na construção de uma consciência crítica em relação ao mundo que a cerca (SASSERON; CARVALHO, 2008).

Sasseron e Carvalho (2011) afirmaram a existência de convergência entre diversas classificações da AC. Agruparam, então, todas as proposições da AC em três eixos estruturantes: (i) compreensão básica de termos, conhecimentos e conceitos científicos fundamentais; (ii) compreensão na natureza das ciências e dos fatores éticos e políticos que circundam sua prática; e (iii) entendimento das relações existentes entre ciência, tecnologia, sociedade e meio -ambiente. O primeiro eixo refere-se à construção de conhecimentos científicos necessários para a interpretação do dia-a-dia através de sua aplicação. Engloba também a compreensão de conceitos-chave, permitindo o entendimento de pequenas informações e situações do cotidiano.

[...] concerne na possibilidade de trabalhar com os alunos a construção de conhecimentos científicos necessários para que seja possível a eles aplicá-los em situações diversas e de modo apropriado em seu dia-a-dia. Sua importância reside ainda na necessidade exigida em nossa sociedade de se compreender conceitos-chave como forma de poder entender até mesmo pequenas informações e situações do dia-a-dia (SASSERON; CARVALHO, 2011, p. 75).

O segundo eixo trabalha a ideia de fazer ciência por meio de transformações do conhecimento, que por sua vez se adquire com a análise de dados, síntese e decodificação de resultados; coloca em pauta, ainda, o caráter humano, social e político que circundam a prática científica.

[...] reporta-se, pois, à ideia de ciência como um corpo de conhecimentos em constantes transformações por meio de processo de aquisição e análise de dados, síntese e decodificação de resultados que originam os saberes. Com vista para a sala de aula, nos anos iniciais do Ensino Fundamental, esse eixo fornece-nos subsídios para que o caráter humano e social inerentes às investigações científicas sejam colocados em pauta. Além disso, deve trazer contribuições para o comportamento assumido por alunos e professor sempre que defrontados com informações e conjunto de novas circunstâncias que exigem reflexões e análises considerando-se o contexto antes de tomar uma decisão (SASSERON; CARVALHO, 2011, p. 75). 
O terceiro eixo compreende a relação entre as esferas Ciência, Tecnologia, Sociedade e Meio Ambiente, por meio da qual a solução de um problema em uma dessas áreas pode desencadear um outro problema em outra área.

[...] trata-se da identificação do entrelaçamento entre estas esferas e, portanto, da consideração de que a solução imediata para um problema em uma destas áreas pode representar, mais tarde, o aparecimento de um outro problema associado. Assim, este eixo denota a necessidade de se compreender as aplicações dos saberes construídos pelas ciências considerando as ações que podem ser desencadeadas pela utilização dos mesmos. $O$ trabalho com este eixo deve ser garantido na escola quando se tem em mente o desejo de um futuro sustentável para a sociedade e o planeta (SASSERON; CARVALHO, 2011, p. 76).

Para a análise desta pesquisa, estabeleceram-se três categorias teóricas para a AC, as quais se definem, respectivamente, nos eixos estruturantes supracitados, são elas: termos, conhecimentos e conceitos científicos fundamentais; natureza da ciência e dos fatores éticos e políticos; e, ciência tecnologia, sociedade e meio-ambiente. Diante da abrangência dessas categorias teóricas, percebe-se a convergência das diversas orientações, objetivos, perspectivas e proposições da AC. Esta percepção fez dessas categorias a lente escolhida para a análise de dados deste trabalho.

Considerando a importância da AC enquanto proposta para o ensino de ciências, torna- se importante compreender se os instrumentos, comumente utilizados para avaliar a aprendizagem em ciências na educação básica, possibilitam conhecer em que medida os alunos foram alfabetizados cientificamente. Esta pesquisa tem seu foco voltado para o Exame Nacional do Ensino Médio (ENEM).

\section{Novo ENEM}

O Exame Nacional do Ensino Médio (ENEM) criado em 1998 pelo Instituto Nacional de Estudos e Pesquisas Educacionais Anísio Teixeira (INEP), do Ministério da Educação, é um exame individual e de caráter voluntário. É oferecido anualmente aos concluintes e egressos do ensino médio, com o objetivo de possibilitar uma referência para autoavaliação, de acordo com as competências e habilidades que o estruturam. Pode ser também utilizado como modalidade alternativa ou complementar aos processos de seleção para o acesso ao ensino superior (INEP, 2005). As diretrizes que orientam a estruturação do exame são baseadas nos Parâmetros Curriculares Nacionais para o Ensino Médio (PCNEM) e nas Orientações Educacionais Complementares aos Parâmetros Curriculares Nacionais (PCN+). Segundo a fundamentação teórico-metodológica do ENEM (INEP, 2005), o modelo de avaliação do mesmo foi desenvolvido buscando-se atrelar aspectos científicos, sociais e tecnológicos.

A partir de 2009 as universidades públicas puderam optar entre quatro possibilidades de utilização desse exame como processo seletivo para ingresso na educação superior: como fase única, como primeira fase, combinado com o vestibular da instituição, como fase única para as vagas remanescentes do vestibular. Esta iniciativa caracterizou o exame nacional como 
"novo ENEM", o qual passou a ser composto por quatro testes, um por área do conhecimento (Linguagem, códigos e suas tecnologias, Ciências humanas e suas tecnologias, Ciências da natureza e suas tecnologias, e, Matemática e suas tecnologias).

De acordo com a matriz de referência do novo ENEM (INEP, 2009), os eixos cognitivos comuns a todas as áreas de conhecimento são dominar linguagens, compreender fenômenos, tomar decisões e enfrentar situações-problema, construir argumentação consistente e elaborar propostas de intervenção. Cada área de conhecimento possui competências e habilidades. No que se refere à química, são elencadas seis áreas de competências (INEP, 2009).

A competência de área 1 engloba a compreensão das ciências naturais e das tecnologias a elas associadas como construções humanas, percebendo seus papéis nos processos de produção e no desenvolvimento econômico e social da humanidade. A competência de área 2 consiste em identificar a presença e aplicar as tecnologias associadas às ciências naturais em diferentes contextos. Associar intervenções que resultam em degradação ou conservação ambiental a processos produtivos e sociais e a instrumentos ou ações científico-tecnológicos, é a competência de área 3. A competência de área 4 refere-se à compreensão das interações entre organismos e ambiente, em particular aquelas relacionadas à saúde humana, relacionando conhecimentos científicos, aspectos culturais e características individuais. Enquanto que competência de área 5 consiste em entender métodos e procedimentos próprios das ciências naturais e aplicá-los em diferentes contextos. As competências das áreas 6, 7 e 8 consistem em apropriar-se de conhecimentos da física, química e biologia, respectivamente, para interpretar, avaliar ou planejar intervenções científico-tecnológicas em situações problema.

Com o papel democratizador do acesso às vagas federais de ensino superior e possibilitador da mobilidade acadêmica, o ENEM passou a ser o principal veículo de acesso às Instituições de Ensino Superior (IES) a partir de 2009. Desde então, pesquisas sobre esse exame têm sido realizadas. Por exemplo, Maceno et al. (2011) analisou o que é preconizado na matriz de referência do novo ENEM para a área de Ciências da Natureza e suas Tecnologias e nos objetos de conhecimento (anexos à matriz). Identificou divergência entre os referidos documentos e apontou para a possibilidade de inviabilização do alcance dos objetivos da reestruturação do ENEM em induzir mudanças curriculares e pedagógicas.

Nas pesquisas de Costa, Santos e Silva (2016) e Cintra, Marques Junior e Sousa (2015), foram analisados os itens de química das edições de 2009 a 2013 do ENEM. O primeiro discutiu as possíveis compreensões sobre interdisciplinaridade nos itens de química. E, através da análise textual discursiva, constataram que em nenhuma prova prevaleceram os itens com aspectos interdisciplinares e sim os itens específicos de química. Os autores apontaram a necessidade de uma maior atenção na formulação das provas no tocante ao emprego adequado da interdisciplinaridade. Já a segunda pesquisa, utilizando-se da Taxonomia de Bloom Revisada, promoveu uma classificação das demandas cognitivas e da dimensão do conhecimento solicitadas por cada item. Dessa forma, analisou a existência ou não de concordância entre as provas e a matriz de referência do exame. Os resultados mostraram um distanciamento entre o que é sugerido pelo documento de referência e o que é observado nos instrumentos avaliativos.

A pesquisa em tela se propõe a dialogar e a avançar em relação às pesquisas supracitadas. Dialoga no momento que também discute a coerência interna do exame, construindo uma análise a respeito do que se propõe na matriz de referência e o que se verifica nos itens. $\mathrm{E}$ avança no instante em que realiza análise a respeito de um tema ainda não abordado, qual 
seja, a relação entre o ENEM e a AC. Assim, o principal objetivo desta pesquisa é verificar em que medida os itens de química do novo ENEM (2009-2015) permitem avaliar a AC. Para isso, serão explicitados os aspectos referentes à $\mathrm{AC}$ contemplados na matriz de referência e, depois, será analisado se esses aspectos estão presentes nos itens de química.

\section{O Método}

A escolha pelos itens de química do ENEM como objeto de estudo deu-se em função da importância desse exame enquanto caminho de acesso ao ensino superior. As provas analisadas foram as do caderno 1 (azul), do período de 2009 a 2015. No ano de 2010 foram consideradas as duas aplicações do exame (2010/1 e 2010/2).

O método de pesquisa adotado foi qualitativo (BOGDAN; BIKLEN, 1994), tendo a análise de conteúdo (BARDIN, 2000) como estratégia para tratamento dos dados. Foi realizada categorização temática das competências e das habilidades referentes ao conteúdo curricular química constantes na matriz de referência e, posteriormente, dos itens de química do ENEM, tendo como parâmetro as categorias teóricas estabelecidas previamente: termos, conhecimentos e conceitos científicos fundamentais, natureza da ciência e dos fatores éticos e políticos, e, ciência, tecnologia, sociedade e meio ambiente. Todo o método foi executado em quatro etapas.

$\mathrm{Na}$ primeira etapa fez-se a identificação das competências e habilidades da matriz de referência do novo ENEM que correspondem ao conteúdo curricular química. Esse processo foi realizado separadamente por dois juízes, obtendo-se 100\% de concordância. Na segunda etapa, com as competências e habilidades identificadas, realizou-se, sua categorização. Cada competência e habilidade foi distribuída em turnos. Foi considerado como turno cada parte textual ou todo o texto da competência ou habilidade que remete diretamente às proposições de uma categoria teórica, seja a um dos aspectos da categoria teórica ou ao conjunto deles. Essa etapa da análise foi realizada separadamente por dois juízes, obtendo-se uma concordância de $100 \%$. O Quadro 1 demonstra como os dados foram tratados e organizados. Na coluna identificação a letra $\mathrm{C}$ se refere à competência, seguida do número referente à sua área (ex.: competência de área 1 - C1) e a letra $\mathrm{H}$ se refere à habilidade seguida do número presente na matriz de referência.

Quadro 1. Tratamento das competências e habilidades da matriz de referência do novo ENEM

\begin{tabular}{|c|c|l|l|}
\hline Turno & Identificação & \multicolumn{1}{|c|}{ Unidade de Significado } & \multicolumn{1}{|c|}{ Categoria } \\
\hline 1 & C1 & $\begin{array}{l}\text { Compreender as ciências naturais e as tecnologias } \\
\text { a elas associadas como construções humanas. }\end{array}$ & $\begin{array}{l}\text { Natureza da ciência e dos } \\
\text { fatores éticos e políticos. }\end{array}$ \\
\hline 2 & C1 & $\begin{array}{l}{[. .] \text { percebendo seus papéis nos processos de }} \\
\text { produção e no desenvolvimento econômico e } \\
\text { social da humanidade. }\end{array}$ & $\begin{array}{l}\text { Ciência, tecnologia, } \\
\text { sociedade e meio } \\
\text { ambiente. }\end{array}$ \\
\hline 3 & H2 & $\begin{array}{l}\text { Associar a solução de problemas de comunicação, } \\
\text { transporte, saúde ou outro, com o correspondente } \\
\text { desenvolvimento científico e tecnológico. }\end{array}$ & $\begin{array}{l}\text { Ciência, tecnologia, } \\
\text { sociedade e meio } \\
\text { ambiente. }\end{array}$ \\
\hline
\end{tabular}

Fonte: elaborado pelos autores. 
Como pode ser visto no Quadro 1, uma mesma competência foi dividida em duas partes, as quais foram atribuídas a categorias teóricas distintas. Isso ocorreu com a competência de área 1 e com a habilidade 25, sendo cada uma de suas partes atribuídas a um turno diferente. Portanto a quantidade total de competências e habilidades identificadas como relacionadas à área de química é menor que a quantidade total de turnos.

$\mathrm{Na}$ terceira etapa, fez-se a identificação dos itens de química, partindo-se do princípio de que fossem necessários conhecimentos da área da química para a resolução do problema proposto pelo enunciado, independente da contextualização feita no texto base da questão, uma vez que esta pode abordar outra área de conhecimento. Esse processo de identificação dos itens foi realizado, separadamente, por dois juízes, obtendo-se $100 \%$ de concordância.

$\mathrm{Na}$ quarta etapa, fez-se a categorização dos itens de química. Os itens foram divididos em turnos que constituem-se em trechos transcritos destes. Para cada turno foi identificada uma unidade de significado que corresponde a trechos textuais dos itens que remetem, direta ou indiretamente, aos conhecimentos, raciocínios e habilidades necessárias, aos alunos, para a sua correta resolução. Todo o conjunto do item (texto base, enunciado e alternativas) foi analisado em busca dessa unidade de significado. Ao final, as unidades de significado foram atribuídas às categorias teóricas adotadas. Essa etapa realizada separadamente por dois juízes, obtendo-se uma concordância de 95\%. O Quadro 2 demonstra como os dados foram tratados e organizados.

Quadro 2. Tratamento dos itens de química do novo ENEM (2009 a 2015)

\begin{tabular}{|c|c|c|c|c|}
\hline \multicolumn{5}{|c|}{ ENEM 2009} \\
\hline Turno & $\begin{array}{c}\text { Item } \\
\mathbf{N}^{\mathbf{o}}\end{array}$ & Trecho do item & $\begin{array}{l}\text { Unidade de } \\
\text { significado }\end{array}$ & Categoria \\
\hline 1 & 1 & $\begin{array}{l}\text { Mais recentemente, outro fator tornou- } \\
\text { se diretamente envolvido no aumento da } \\
\text { concentração de CO2 na atmosfera: o } \\
\text { desmatamento. Considerando o texto, uma } \\
\text { alternativa viável para combater o efeito } \\
\text { estufa é: }\end{array}$ & $\begin{array}{l}\text { Considerando o } \\
\text { texto, uma alternativa } \\
\text { viável para combater } \\
\text { o efeito estufa é: }\end{array}$ & $\begin{array}{l}\text { Ciência, } \\
\text { tecnologia, } \\
\text { sociedade e } \\
\text { meio ambiente. }\end{array}$ \\
\hline 2 & 12 & $\begin{array}{l}\text { Uma vez que o ácido carboxílico formado } \\
\text { é pouco solúvel em água e menos eficiente } \\
\text { na remoção de gorduras, o pH do meio } \\
\text { deve ser controlado de maneira a evitar } \\
\text { que o equilíbrio acima seja deslocado para } \\
\text { a direita. Com base nas informações do } \\
\text { texto é correto concluir que os sabões } \\
\text { atuam de maneira: Alternativa letra (a) } \\
\text { mais eficiente em pH básico. }\end{array}$ & $\begin{array}{l}\text { Com base nas } \\
\text { informações do } \\
\text { texto, é correto } \\
\text { concluir que os } \\
\text { sabões atuam de } \\
\text { maneira: Alternativa } \\
\text { letra } \\
\text { (a) mais eficiente em } \\
\text { pH básico. }\end{array}$ & $\begin{array}{l}\text { Termos, } \\
\text { conhecimentos } \\
\text { e conceitos } \\
\text { científicos } \\
\text { fundamentais. }\end{array}$ \\
\hline
\end{tabular}

Fonte: elaborado pelos autores.

Como pode ser visto no Quadro 2, a unidade de significado do turno 2 apresenta uma das alternativas de resposta presentes no item 12 do exame aplicado em 2009, a qual se refere ao gabarito do item. Isso se faz necessário para mostrar, de forma clara, o raciocínio que a questão exige do aluno para resolvê-la e, portanto, a qual categoria teórica da AC ela estaria incluída. O mesmo ocorreu em outras questões analisadas. 


\section{Resultados e Discussão}

\section{A matriz de referência do novo ENEM}

Na leitura da matriz de referência do novo ENEM são explicitadas oito competências de área e vinte e sete habilidades, dentro da área de Ciências da Natureza e suas Tecnologias. Dessas, cinco competências de área e dezessete habilidades referem-se aos conteúdos curriculares de química (Quadro 3).

Quadro 3. Resultado da identificação das competências e habilidades da área de química

\begin{tabular}{|l|l|c|}
\hline & \multicolumn{1}{|c|}{ Numeração na matriz } & Total \\
\hline Competências de área & $1,2,3,5,7$ & 5 \\
\hline Habilidades & $2,3,4,6,7,8,9,10,12,17,18,19,24,25,26,27$ & 16 \\
\hline
\end{tabular}

Fonte: elaborado pelos autores.

O resultado da categorização, na análise de conteúdo, das competências e habilidades da matriz de referência do novo ENEM está apresentado no Quadro 4.

Quadro 4. Distribuição das competências e habilidades por categorias teóricas

\begin{tabular}{|l|c|c|}
\hline \multicolumn{1}{|c|}{ Categorias } & Total de turnos & Quantidade relativa \\
\hline Termos, conhecimentos e conceitos científicos fundamentais & 4 & $17,4 \%$ \\
\hline Natureza da ciência e dos fatores éticos e políticos & 4 & $17,4 \%$ \\
\hline Ciência tecnologia, sociedade e meio ambiente & 15 & $65,2 \%$ \\
\hline
\end{tabular}

Fonte: elaborado pelos autores.

Após a categorização, foi encontrado que 17,4\% das competências e habilidades correspondem a proposições da AC constantes na categoria teórica Termos, conhecimentos e conceitos científicos fundamentais. Algumas das competências e habilidades aqui agrupadas foram: "Apropriar-se de conbecimentos da química para, em situaçoes problema, interpretar, avaliar ou planejar intervenções científico-tecnológicas" (C7) e "Utilizar códigos e nomenclatura da química para caracterizar materiais, substâncias ou transformações químicas" (C7, H24).

Com relação à segunda categoria teórica, Natureza da ciência e dos fatores éticos e políticos, suas proposições estão contempladas em 17,4\% das competências e habilidades. Algumas delas são: "Compreender as ciências naturais e as tecnologias a elas associadas como construções humanas [...]" (C1) e "Entender métodos e procedimentos próprios das ciências naturais e aplicá-los em diferentes contextos" (C1, H5).

Por fim, 65,2\% das competências e habilidades correspondem a proposições da AC pertencentes à categoria Ciência tecnologia, sociedade e meio ambiente. Por exemplo: "Avaliar métodos, processos on procedimentos das ciências naturais que contribuam para diagnosticar ou solucionar problemas de ordem social, econômica ou ambiental" (C5, H19) e "Avaliar propostas de intervenção no meio ambiente aplicando conbecimentos quimicos, observando riscos ou beneficios" (C7, H27). 
Os resultados encontrados demonstram que, conquanto o novo ENEM não faça referência nominal à $\mathrm{AC}$, diversas das competências e habilidades encontradas em sua matriz de referência correspondem a proposições da AC, podendo ser localizadas nas categorias teóricas adotadas.

\section{Os itens de química do novo ENEM}

A relação entre o ano, número e quantidade de itens identificados como sendo da área de química (total de 119 itens) encontram-se no Quadro 5 a seguir. Nela é possível localizar e obter uma visão geral da distribuição dos itens de química nas oito provas do novo ENEM.

Quadro 5. Resultado da identificação dos itens de química nos exames de 2009 a 2015

\begin{tabular}{|c|l|c|c|l|c|}
\hline Ano & \multicolumn{1}{|c|}{ Número do item } & $\begin{array}{l}\text { Total de } \\
\text { Itens }\end{array}$ & Ano & \multicolumn{1}{|c|}{ Número do item } & $\begin{array}{c}\text { Total de } \\
\text { Itens }\end{array}$ \\
\hline 2009 & $\begin{array}{l}1,12,15,23,26,29,34,36, \\
43,44\end{array}$ & 10 & 2012 & $\begin{array}{l}46,49,53,58,59,63,66,69, \\
70,76,79,82,84,86,89,90\end{array}$ & 16 \\
\hline $2010 / 1$ & $\begin{array}{l}52,53,55,58,60,62,65,67, \\
69,72,73,74,77,80,82,83, \\
85,90\end{array}$ & 18 & 2013 & $\begin{array}{l}47,49,51,54,58,64,67,68, \\
69,71,74,77,81,86,90\end{array}$ & 15 \\
\hline $2010 / 2$ & $\begin{array}{l}53,56,60,62,65,73,74,75, \\
76,77,79,80,82,83,87,89, \\
90\end{array}$ & 17 & 2014 & $\begin{array}{l}48,49,51,56,58,59,63,65, \\
66,70,77,78,80,83,86,88\end{array}$ & 16 \\
\hline 2011 & $\begin{array}{l}50,51,52,54,55,58,59,72, \\
75,80,81,83,85\end{array}$ & 13 & 2015 & $\begin{array}{l}46,51,52,55,57,58,59,60, \\
62,71,73,76,77,80,81,84,90\end{array}$ & 17 \\
\hline
\end{tabular}

Fonte: elaborado pelos autores.

O resultado da categorização dos itens de química é apresentado no Quadro 6. Vale ressaltar que os itens 60, 89 e 90 da prova do ENEM de 2010/2 não se enquadraram em nenhuma das categorias teóricas, pois a habilidade exigida para sua resolução é a de interpretação textual, onde o aluno precisa saber relacionar o texto do enunciado com as alternativas de resposta sem a necessidade de algum conhecimento na área avaliada (química) ou de temáticas pertinentes às categorias teóricas adotadas.

O Quadro 6 mostra que nenhuma questão de química das oito provas do ENEM analisadas mensura conhecimentos na perspectiva da categoria teórica Natureza da ciência e dos fatores éticos e políticos. Nesta categoria estariam incluídos os turnos dos itens que trabalhassem a ideia de fazer ciência por meio de transformações do conhecimento, que por sua vez se adquire com a análise de dados, síntese e decodificação de resultados, colocando em pauta, ainda, o caráter humano, social e político que circundam a prática científica. 
Quadro 6. Distribuição dos itens de química por categorias teóricas

\begin{tabular}{|l|c|c|c|c|c|c|c|c|c|}
\hline \multicolumn{1}{|c|}{ Categorias } & \multicolumn{7}{c|}{ Total de turnos por ano } & $\begin{array}{c}\text { Total de } \\
\text { turnos }\end{array}$ \\
\cline { 2 - 12 } & $\mathbf{2 0 0 9}$ & $\mathbf{2 0 1 0 / 1}$ & $\mathbf{2 0 1 0 / 2}$ & $\mathbf{2 0 1 1}$ & $\mathbf{2 0 1 2}$ & $\mathbf{2 0 1 3}$ & $\mathbf{2 0 1 4}$ & $\mathbf{2 0 1 5}$ & \\
\hline $\begin{array}{l}\text { Termos, conhecimentos } \\
\text { e conceitos científicos } \\
\text { fundamentais }\end{array}$ & 8 & 16 & 12 & 9 & 15 & 13 & 14 & 16 & 103 \\
\hline $\begin{array}{l}\text { Natureza da ciência e dos } \\
\text { fatores éticos e políticos }\end{array}$ & 0 & 0 & 0 & 0 & 0 & 0 & 0 & 0 & 0 \\
\hline $\begin{array}{l}\text { Ciência tecnologia, sociedade } \\
\text { e meio ambiente }\end{array}$ & 2 & 2 & 2 & 4 & 1 & 2 & 2 & 1 & 16 \\
\hline
\end{tabular}

Fonte: elaborado pelos autores.

Na primeira categoria - Termos, conhecimentos e conceitos científicos fundamentais - foram atribuídos os turnos cujos itens abordam a construção de conhecimentos científicos necessários para a interpretação do dia-a-dia através de sua aplicação. Engloba também aqueles itens que necessitam que o aluno compreenda conteúdos e conceitos-chave, permitindo o entendimento de pequenas informações e situações do cotidiano. A seguir, um exemplo da questão 12, à qual foi atribuída essa categoria teórica.

Sabões são sais de ácidos carboxílicos de cadeia longa utilizados com a finalidade de facilitar, durante processos de lavagem, a remoção de substâncias de baixa solubilidade em água, por exemplo, óleos e gorduras. A figura a seguir representa a estrutura de uma molécula de sabão [...] Em solução, os ânions do sabão podem hidrolisar a água e, desse modo, formar o ácido carboxílico correspondente. Por exemplo, para estearato de sódio, é estabelecido o seguinte equilíbrio [...] Uma vez que o ácido carboxílico formado é pouco solúvel em água e menos eficiente na remoção de gorduras, o $\mathrm{pH}$ do meio deve sercontrolado de maneira a evitar que o equilíbrio acima seja deslocado para a direita. Com base nas informações do texto, é correto concluir que os sabões atuam de maneira: (a) mais eficiente em pH básico. (b) mais eficiente eh $\mathrm{pH}$ ácido. (c) mais eficiente em $\mathrm{pH}$ neutro. (d) eficiente em qualquer faixa de $\mathrm{pH}$. (e) mais eficiente em $\mathrm{pH}$ ácido ou neutro. (ENEM, 2009, p. 4).

A questão acima transcrita exige que o aluno saiba interpretar as informações a respeito da eficiência do ácido carboxílico na remoção de gorduras e a reação de equilíbrio apresentadas no enunciado. É necessário ainda que o aluno saiba: identificar os reagentes químicos a partir de sua fórmula estrutural, as consequências da perturbação de um equilíbrio químico, a escala e o conceito de $\mathrm{pH}$. Todas essas habilidades necessárias na resolução da questão permitem que o aluno entenda essa pequena situação do cotidiano: de lavar louça.

$\mathrm{Na}$ terceira categoria - Ciência, tecnologia, sociedade e meio ambiente - foram atribuídos os turnos cujos itens abordam a relação entre essas quatro esferas, por meio da qual a 
solução de um problema em uma dessas áreas pode desencadear um outro problema em outra área. Engloba também a necessidade de compreender as aplicações dos saberes construídos pelas ciências e considerar os possíveis desencadeamentos de sua utilização. A seguir, um exemplo de questão a qual foi atribuída essa categoria teórica.

Os corais que formam o banco dos Abrolhos, na Bahia, podem estar extintos até 2050 devido a uma epidemia. Por exemplo, os corais-cérebro já tiveram cerca de $10 \%$ de sua população afetada pela praga-branca, a mais prevalente das seis doenças identificadas em Abrolhos, causada provavelmente por uma bactéria. Os cientistas atribuem a proliferação das patologias ao aquecimento global e à poluição marinha. $\mathrm{O}$ aquecimento global reduziria a imunidade dos corais ou estimularia os patógenos causadores desses males, trazendo novos agentes infecciosos. A fim de combater a praga-branca, a medida mais apropriada, segura e de efeitos mais duradouros seria: (a) aplicar antibióticos nas águas litorâneas de Abrolhos. (b) substituir os aterros sanitários por centros de reciclagem de lixo. (c) introduzir nas águas de Abrolhos espécies que se alimentam da bactéria causadora da doença. (d) aumentar, mundialmente, o uso de transportes coletivos e diminuir a queima de derivados de petróleo. (e) criar uma lei que proteja os corais impedindo que mergulhadores e turistas se aproximem deles e os contaminem. (ENEM, 2010, p. 26).

A questão acima transcrita exige que o aluno saiba interpretar o texto base e identificar o aquecimento global e a poluição marinha como os fenômenos a serem minimizados. Diante disso, o aluno deve julgar qual a medida mais apropriada para a solução do problema apresentado. A habilidade de julgar a melhor alternativa para resolução da questão exige que o aluno saiba articular as esferas de ciência, tecnologia, sociedade e meio ambiente de forma crítica e prática.

Dentre os demais julgamentos a serem feitos esperam-se o de inaplicabilidade e falta de segurança ao aplicar antibióticos nas águas litorâneas de Abrolhos; identificação de medida pouco apropriada e ineficiência ao substituir os aterros sanitários por centros de reciclagem de lixo; pouca durabilidade ao introduzir espécies que se alimentem da bactéria causadora da doença e ineficiência na criação da lei.

De acordo com os dados do Quadro 6 evidencia-se que a maioria significativa dos itens de química das oito provas contempla a categoria teórica Termos, conhecimentos e conceitos científicos fundamentais. Enquanto uma minoria, também apresentada em todas as oito provas, contempla a categoria teórica Ciência, tecnologia, sociedade e meio ambiente. As proposições da categoria teórica Natureza da ciência e dos fatores éticos e políticos não foram encontradas nos itens de química das oito provas analisadas. A Figura 1 mostra a quantidade percentual de cada categoria teórica para cada prova do ENEM.

Como a distribuição porcentual das categorias teóricas respeitou a mesma tendência em todos os anos, é conveniente analisá-la de forma geral por meio da Figura 2. 
Figura 1. Distribuição percentual dos turnos por categorias teóricas

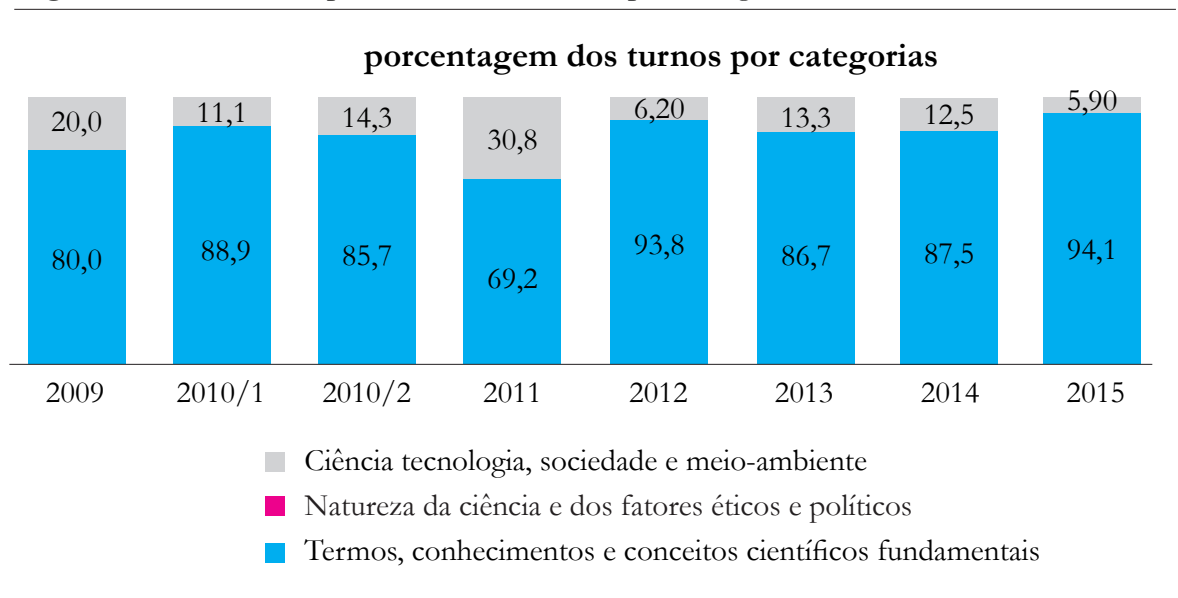

Fonte: elaborado pelos autores.

Figura 2. Distribuição porcentual geral (2009-2015) das categorias teóricas

porcentagem dos turnos (2009-2015)

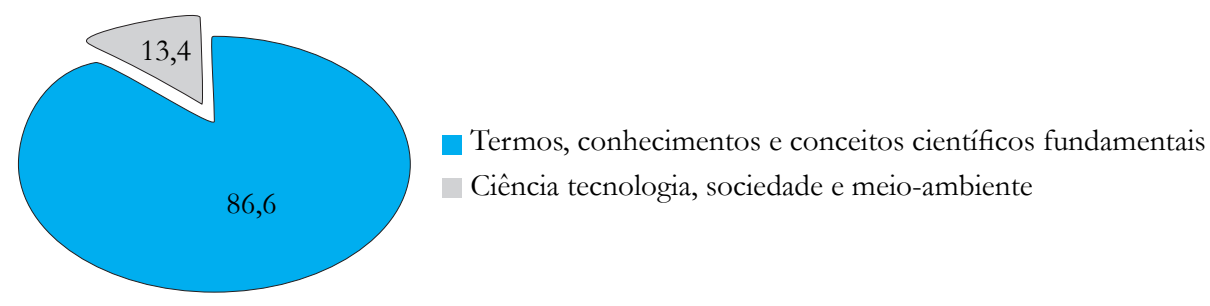

Fonte: elaborado pelos autores.

Nota-se que $86,6 \%$ de todos os itens de química dos exames aplicados no período analisado contemplam as proposições referentes à categoria teórica Termos, conhecimentos e conceitos científicos fundamentais. Enquanto que 13,4\% contemplam as proposições referentes à categoria teórica Ciência, tecnologia, sociedade e meio ambiente.

Importante ressaltar que, como explicitado anteriormente, as competências e habilidades referentes ao conteúdo curricular química preconizadas na matriz de referência do novo ENEM contemplam as proposições das três categorias teóricas adotadas. Contudo as relações percentuais não se mantêm quando se compara a matriz e os itens dos exames, respectivamente, $17,4 \% \mathrm{e}$ $86,6 \%$ para a categoria teórica Termos, conhecimentos e conceitos científicos fundamentais; $65,2 \%$ e 13,4\% para a categoria teórica Ciência, tecnologia, sociedade e meio ambiente; e 17,4\% e $0 \%$ para a categoria teórica Natureza da ciência e dos fatores éticos e políticos. 
Diante disso, não se percebe uma continuidade entre a matriz e o exame. Mais do que isso, se nenhum item de química avalia proposições referentes a última categoria, então as habilidades e competências contidas na matriz de referência que contemplam tais proposições também não são avaliadas pelo exame.

Nesta pesquisa, assim como Maceno et al. (2011) e Cintra, Marques Junior e Sousa (2015), encontramos divergências internas no ENEM. No caso aqui analisado, elas se referem a descontinuidades entre a matriz curricular e os itens de química. E, de maneira similar ao que é sinalizado por Costa, Santos e Silva (2016) com respeito à interdisciplinaridade, recomenda- se maior atenção na formulação dos itens de química de maneira a se contemplar a diversidade dos aspectos presentes na matriz de referência pertinentes à AC.

\section{Considerações Finais}

O objetivo desta pesquisa foi verificar em que medida o ENEM permite avaliar a alfabetização científica. Para isso, utilizou-se uma abordagem qualitativa de pesquisa na análise da matriz de referência e dos itens de química do novo ENEM (2009-2015). Os resultados obtidos com esse estudo revelaram informações importantes acerca da matriz de referência do novo ENEM em contraste com os itens de química do exame.

A primeira delas é a existência de divergências entre o que é proposto na matriz e o que de fato é avaliado pelos itens de química. Os resultados mostraram alterações quanto à abordagem das competências e habilidades constantes na matriz, referentes à área de química, seja no quantitativo com que são contempladas (diferenças percentuais), seja quanto à sua tipologia (categorias da AC).

Ainda, fica explícito que as proposições da AC mais enfatizadas pelas propostas na matriz não correspondem àquelas mais avaliadas. Chama atenção que $17,4 \%$ das competências e habilidades na matriz são referentes à categoria Natureza da ciência e dos fatores éticos e políticos, que por sua vez não é avaliada em qualquer item de química. Essa constatação sugere uma transgressão dos itens de química em relação ao disposto na matriz de referência do novo ENEM.

Sabe-se que o processo de elaboração de questões do ENEM envolve um curso de capacitação e a disponibilização de orientações sobre como proceder para a criação dos itens. Nesse contexto, a pesquisa em tela fornece conhecimentos que possibilitam estudos futuros questionarem a respeito do porquê não há continuidade entre o que a matriz de referência propõe e o que se encontra nos itens. O que acontece no caminho que leva da matriz de referência ao item? No caso do aspecto aqui analisado, por exemplo, parece que ainda há uma valorização de uma perspectiva conteudista, uma vez que, ao contrário da matriz de referência, a categoria mais presente nos itens é a que se refere mais diretamente ao conteúdo específico. Porém isso é uma hipótese a ser problematizada em pesquisas futuras.

Os resultados aqui encontrados podem embasar outros questionamentos e investigações acerca da formulação e utilização do ENEM. Dentre os quais é possível citar trabalhos equivalentes a este, utilizando os itens das demais áreas específicas; ou o estudo da coerência interna, elencando outros aspectos além da AC, interdisciplinaridade etc. 
Por fim, vale reforçar que o novo ENEM não se propõe, explicitamente, a avaliar a AC daqueles que o fazem. Contudo, já que algumas proposições da AC estão presentes na matriz de referência, recomenda-se que o exame avalie de forma significativa todas essas proposições. Uma vez que o ENEM se apresenta como influenciador na reformulação de currículos na educação básica, seguir essa recomendação levaria para dentro de sala de aula uma maior qualidade de ensino na perspectiva da AC e da formação do cidadão política, econômica, social e cientificamente consciente e ativo.

\section{Referências}

BARDIN, L. Análise de conteúdo. Lisboa: Edições 70, 2000.

BOGDAN, R.; BIKLEN, S. Investigação qualitativa em educação: uma introdução à teoria e aos métodos. Porto: Porto Editora, 1994.

CHASSOT, A. Alfabetização científica: uma possibilidade para a inclusão social. Revista Brasileira de Educação, Rio de Janeiro, n. 22, p. 89-100, 2003. Disponível em: <http:/ / dx.doi.org/10.1590/S1413-24782003000100009>. Acesso em: 24 jun. 2015.

CINTRA, E. O.; MARQUES JUNIOR, A. C.; SOUSA, E. C. Correlação entre a matriz de referência e os itens envolvendo conceitos de química presentes no ENEM de 2009 a 2013. Ciência e Educação, Bauru, v. 22, n. 3, p. 707-725, 2015. Disponível em: <http://dx.doi. org/10.1590/1516-731320160030010>. Acesso em: 4 maio 2018.

COSTA, E. S. C.; SANTOS, M. L.; SILVA, E. L. Abordagem da química no novo ENEM: uma análise acerca da interdisciplinaridade. Química Nova na Escola, São Paulo, v. 38, n. 2, p. 112-120, 2016. Disponível em: <http://dx.doi.org/10.5935/0104-8899.20160015>. Acesso em: 4 maio 2018.

ENEM 2009: prova de ciências da natureza e suas tecnologias. 2009. Disponível em: <http://download.inep.gov.br/educacao_basica/enem/downloads/2009/dia1_caderno1. pdf>. Acesso em: 4 maio 2018.

ENEM 2010: 2a aplicação: prova de ciências humanas e suas tecnologias. 2010. Disponível em: < http://public.inep.gov.br/enem/2010/AZUL_quarta-feira_GAB.pdf>. Acesso em: 4 maio 2018.

INEP. Exame nacional do ensino médio (ENEM): fundamentação teórico-metodológica. Brasília, 2005. Disponível em: <https://tinyurl.com/yayalqr4>. Acesso em: 4 maio 2018.

INEP. Matriz de referência para o ENEM 2009. Brasília, 2009. Disponível em: <http:// ensinomediodigital.fgv.br/resources/pdf/matriz_novoenem.pdf $>$. Acesso em: 4 maio 2018.

LAUGKSCH, R. C. Scientific literacy: a conceptual overview. New York: John Wiley, 2000.

LEAL, M. C.; SOUZA, G. G. Narrativa, mito, ciência e tecnologia: o ensino de ciências na escola e no museu. Ensaio: pesquisa em educação em ciências, Belo Horizonte, v. 2, n. 1, p. 1-29, 2002. 
LORENZETTTI, L.; DELIZOICOV, D. Alfabetização científica no contexto das séries iniciais. Ensaio: pesquisa em educação em ciências, Belo Horizonte, v. 3, n. 1, p. 1-17, 2001.

MACENO, N. G. et al. A matriz de referência do ENEM 2009 e o desafio de recriar o currículo de química na educação básica. Química Nova na Escola, São Paulo, v. 33, n. 3, p. 153-159, 2011.

MILARÉ, T.; RICHETTTI, G. P. Alfabetização científica no ensino de química: um olhar sobre os temas sociais. In: ENCONTRO NACIONAL DE ENSINO DE QUÍMICA, 14., 2008, Curitiba. Anais... Disponível em: <http://www.quimica.ufpr.br/eduquim/eneq2008/ resumos/R0717-2.pdf>. Acesso em: 4 maio 2018.

NIEZER, T. M.; SILVEIRA, R. M. C. F.; SAUER, E. A utilização de revistas de divulgação científica no ensino de química em um enfoque ciência-tecnologia-sociedade visando a alfabetização científica e tecnológica. Atos de Pesquisa em Educação, Blumenau, v. 7, n. 3, p. 877-899, 2012. Disponível em: <http://proxy.furb.br/ojs/index.php/ atosdepesquisa/article/view/3471/2183>. Acesso em: 20 mar. 2015.

ROSA, D. C.; TERRAZZAN, E. A. Ensinando ciências naturais numa perspectiva de alfabetização científico-tecnológica. In: ENCONTRO NACIONAL DE PESQUISA EM ENSINO DE CIÊNCIAS, 3., 2001, Atibaia. Anais... Disponível em: < http://www.nutes. ufrj.br/abrapec/iiienpec/Atas\%20em\%20html/o58.htm\#o58>. Acesso em: 20 mar. 2015.

SASSERON, L. H.; CARVALHO, A. M. P. Alfabetização científica: uma revisão bibliográfica. Investigações em Ensino de Ciências, Porto Alegre, v. 16, n. 1, p. 59-77, 2011. Disponível em: < http://www.if.ufrgs.br/ienci/artigos/Artigo_ID254/v16_n1_a2011. pdf $>$. Acesso em: 20 mar. 2015.

SASSERON, L. H.; CARVALHO, A. M. P. Almejando alfabetização científica no ensino fundamental: a proposição e a procura de indicadores do processo. Investigações em Ensino de Ciências, Porto Alegre, v. 13, n. 3, p. 333-352, 2008.

Artigo recebido em 22/09/2016. Aceito em 26/11/2017.

Contato: Universidade Federal do Rio de Janeiro, Rua Aloisio da Silva Gomes, 50, Granja dos Cavaleiros, Macaé, RJ, CEP: 27930-560, Brasil. 